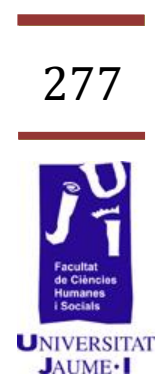

\title{
Introducció a la llengua espanyola
}

\author{
Ma Amparo Garcés Ventura \\ magarven@hotmail.com \\ Santiago Teruel Tomás \\ santiteru@yahoo.es \\ Jessica Marquez Safont \\ jessica.marsaf@gmail.com
}




\section{Resum}

Aquesta experiència que dóna lloc al treball d'investigació que presentem, es centra al CEIP Roca i Alcaide de Borriana. Un centre que vol avançar com a comunitat d'aprenentatge, en una nova etapa, i que tracta de respondre a les necessitats dels seus membres. En aquesta escola vam realitzar el nostre projecte d'aprenentatge servei per a l'assignatura de Didàctica General de segon curs del Grau de Mestre d'Infantil. Per això, en un primer moment vam haver de detectar les necessitats del centre per, posteriorment, centrar el nostre projecte a les famílies $\mathrm{i}$ al seu aprenentatge de la llengua. La nostra pretensió era que les famílies puguen aprendre la llengua espanyola, a la vegada que, nosaltres, participàvem en un dels seus somnis: fer un taller per adquirir la llengua del barri i la de l'escola (valencià i castellà). Dels resultats trobats, destaquem l'alta participació de les famílies en el taller i la absoluta implicació per part del equip directiu perquè el taller es posés en funcionament. Tant per a nosaltres com per a les dones que han participat en aquest projecte ha estat una experiència molt positiva $i$ enriquidora que ha acostat les famílies a l'escola.

Paraules clau: comunitat d'aprenentatge, aprenentatge servei, famílies, participació, implicació.

\section{Introducció}

Amb motiu de la pràctica que havíem de realitzar per a l'assignatura «Didàctica General» basada en l'aprenentatge servei, corresponent al 2 ㅇ curs de Grau mestre d'Educació Infantil, detectem al CEIP Roca i Alcaide de Borriana la necessitat d'integrar als pares en les activitats del centre. Aquest centre és un CAES (Centre d'Acció Educativa Singular) i està en procés de transformació per convertir-se en una Comunitat d'Aprenentatge, sent aquest curs 2012/2013 el segon com a tal. Per aquestes raons vam decidir crear un taller de «Introducció a la llengua espanyola», ja que el $80 \%$ dels alumnes matriculats els pares són d'origen àrab, el $10 \%$ del alumnat precedeixen d'altres països com Romania, Xina..., i el $10 \%$ restant són espanyols, encara que la majoria d'aquests son d'ètnia gitana i d'un nivell sociocultural i econòmic baix. Aquesta situació desencadena en tenir un coneixement de la llengua espanyola bastant limitat, cosa que els dificulta enormement la seua integració social.

Per poder entendre la nostra investigació, en primer $\mathrm{lloc}$ cal contextualitzar i situar teòricament els conceptes que apareixen.

Davant la societat de la informació (Aparici, 2003; Buman, 2007; Castells, 2001) en que ens trobem, el nostre sistema educatiu requerís noves 
formes d'ensenyament-aprenentatge que responguin a les demandes actuals.

Com bé apunta l'informe Delors (1996), no es tracta sols d'aprendre a conèixer, sinó també de aprendre a fer, aprendre a viure y aprendre a ser. Davant d'aquest context, i la importància que l'aprenentatge basat en competències que té el nostre sistema educatiu (LOE, 2006), la OCDE defineix aquest sistema com la combinació d'habilitats pràctiques, coneixements, motivacions, valors ètics, actituds, emocions i altres components socials que es mobilitzen conjuntament per assolir una acció eficaç (Hersh i altres, 1999).

Per tant, definirem el concepte d'aprenentatge servei com una activitat complexa que integra el servei a la comunitat amb l'aprenentatge de continguts, competències, habilitats o valors. En l'aprenentatge servei es fonen intencionalitat pedagògica i intencionalitat solidària. És una proposta innovadora que parteix d'elements tan coneguts com el servei voluntari a la comunitat i l'adquisició d'aprenentatges.

L'aprenentatge servei és una proposta educativa que combina processos d'aprenentatge i de servei a la comunitat en un sol projecte ben articulat en el qual els participants es formen tot treballant sobre necessitats reals de l'entorn amb l'objectiu de millorar-lo.

L'aprenentatge servei és, doncs, un projecte educatiu amb utilitat social.

Ampliant la definició, i segons la Xarxa Telemàtica Educativa de Catalunya (XTEC), l'aprenentatge servei és una metodologia pedagògica que obre els centres educatius a les necessitats socials i reals de la comunitat on es troba. Es vol que el centre s'obri a la vida i seguir sensible als problemes, dificultats o deficiències que presenta el seu entorn proper o més llunyà.

D'altra banda, el centre en què hem desenvolupat el nostre treball es troba en procés de transformació per convertir-se en una comunitat d'aprenentatge. Segons Flecha y Puigvert (2008), en el seu treball «Las comunidades de aprendizaje: Una apuesta por la igualdad educativa» defineix comunitat d'aprenentatge com:

Un projecte de transformació de centres educatius dirigit a la superació del fracàs escolar i l'eliminació de conflictes. Aquest projecte es distingeix per una aposta per l'aprenentatge dialògic mitjançant els grups interactius, on el diàleg igualitari es converteix en un esforç comú per aconseguir la igualtat educativa de tots els alumnes.

La transformació a la que es referix aquest article la trobem en la idea $d^{\prime}$ aconseguir una escola que tots desitgem, on tots tinguem les mateixes oportunitats d'aprenentatge $i$ aconseguir una escola on tots, tant alumnes, mestres i voluntaris caminen tots en una mateixa direcció. A partir d'aquest moment, l'aprenentatge escolar no recau exclusivament 
en mans del professorat, sinó que formarà part i dependrà de la participació de tots els membres de la comunitat educativa, com de les persones o associacions que vulguin participar...

Davant la desigualtat d'aprenentatge i la exclusió en la que es troben moltes persones i collectius, les comunitats d'aprenentatge se consideren com una aposta per la igualtat educativa en el marc de la societat de la informació. És la reivindicació de l'educació que totes les persones volem per a les nostres filles i fills, per a totes les nenes i nens del món.

En el cas de formar part d'un Pla educatiu d'entorn, on ja existeix una diagnosi de necessitats i un projecte que hi actua, aquest és el marc idoni des d'on oferir oportunitats per a l'aprenentatge servei.

L'aprenentatge servei comença amb un exercici d'anàlisi i crítica de la realitat per determinar quin tipus d'intervenció es pot fer per millorar una realitat que en la diagnosi de necessitats s'ha detectat com a negativa.

Aquesta metodologia no es limita a la detecció de les necessitats, sinó que per sobre de tot pretén implicar els joves en la realització d'un servei a la comunitat.

Per designar el que assenyala l'expressió servei a la comunitat s'han fet servir termes com intervenció o participació ciutadana, compromís cívic, ajuda als altres, acció solidària, responsabilitat social o voluntariat. Sigue quina sigue l'expressió que es face servir, per servei entenem una acció real que va més enllà de les paraules o les intencions, i que es centra en la realització d'una contribució a favor de la comunitat, allunyant-se de l'assistència, i buscant en la relació compartida del donar i rebre un llaç d'afecte i de reciprocitat.

Com bé ens diu Paulo Freire (1997) en el seu llibre "La educació com a pràctica de la llibertat» pàgina 14:

La alfabetització, i per tant tota la feina d'educar, sols serà autènticament humanista en la mesura en que es procuri la integració del individu a la seua realitat nacional [...])en la mesura que puga crear en l'educand un procés de recreació, de cerca, de independència i, a la vegada, de solidaritat.

Com a exemple d'aquesta metodologia, trobem al nostre país, i concretament en educació primària, experiències de gran importància pel seu contingut i el seu propi desenvolupament. A l'escola Santa Ana, ubicada al centre de Barcelona, es porta a terme una activitat en que els alumnes de cinquè es reuneix per a cantar cançons populars als més menuts, responsabilitzant-se ells durant el temps que s'ha marcat 
d'ensenyar-les als més petits, recuperant al mateix temps, una tradició catalana (Martín i altres, 2006).

Un altre cas en l'àmbit universitari, l'experiència Amics $i$ amigues de la lectura, realitzada per l'alumnat de les facultats de Pedagogia i Formació del Professorat de la Universitat de Barcelona, ajuden a millorar la competència lectora de xiquets $i$ joves d'educació primària i secundària, realitzant una tasca d'acompanyament i reforç (De la Cerda, Martínez i Puig, 2008).

L'aprenentatge servei vol redescobrir els efectes educatius d'un dinamisme pedagògic bàsic: I'ajut als altres i sentir-se part d'un collectiu. L'ajut mutu, l'altruisme, la solidaritat o la cooperació són alguns dels valors que es troben a la base de la humanització.

\section{Descripció de l'experiència. Taller d' introducció a la llengua espanyola}

El principal objectiu del nostre treball, era aconseguir integrar els pares en activitats del centre i, a més, iniciar un taller de llengua espanyola que, després de les nostres tres sessions, tingués continuïtat durant tot el curs. Aquest taller, també havia de servir com a pont per organitzar altres activitats que proposessin els pares i, així, aconseguir la seva inclusió i participació en el centre, ja que fins ara no se'n havia realitzat cap.

El primer punt del nostre treball consistia en detectar les necessitats del col-legi per a poder, posteriorment, centrar el nostre aprenentatge servei. Per aquest motiu, ens vam desplaçar al centre, i així tindre un primer contacte amb l'equip directiu. Després de mantenir una breu xerrada sobre el funcionament del centre, els vam demanar que ens deixaren entrar en les diferents classes per observar de primera mà les necessitats més urgents.

Davant el gran nombre de necessitats reconegudes, vam decidir demanar consell al director de l'escola. Aquest ens va insistir en que la exigència primordial que tenien, passava per incloure al barri en el centre, i que a més, els seus habitants participaren en l'educació dels nens. El gran dilema es presentava a l'hora de posar en marxa aquest desitjat taller, ja que no sabíem ben bé cóm realitzar-lo. Cal recordar que més del $80 \%$ dels alumnes matriculats són estrangers $i$, els seus progenitors tenen un curt domini de la llengua espanyola.

Encara que la nostra especialitat són els xiquets d'infantil, vam creure que si ajudàvem als pares a millorar, conèixer i desenvolupar-se amb la nostra llengua, indirectament també estaríem ajudant no sols als xiquets 
d'infantil, sinó també a tots els membres de la comunitat educativa del centre.

Després de comunicar al centre que l'aprenentatge-servei anàvem a dirigir-lo als pares, i de passar una circular a tots els tutors sobre el taller que anàvem a desenvolupar, el gran problema que se'ns presentava era la incertesa dels pares que anaven a acudir i el nivell de la llengua que pogueren tindre. Per tant, era feina complicada estructurar la sessió inicial, ja que no comptàvem ni amb la quantitat, ni el nivell dels alumnes.

La preparació del taller va consistir, sobre tot, en comprovar el material didàctic amb què comptava el centre i recopilar tota la informació possible sobre les diferents tàctiques, pràctiques i metodologies per a ensenyar a llegir a persones adultes, qüestió gens fàcil per a uns novells com nosaltres. Una vegada adjuntada tota la informació vam procedir a la programació de la primera sessió del taller.

En aquesta primera sessió ens vam centrar, sobre tot, a esbrinar els coneixements que tenien del castellà tots els assistents, tant a nivell escrit com a nivell oral. Una vegada realitzades les tasques de presentació, els vam plantejar uns exercicis inicials sobre l'aprenentatge del nostre alfabet. Després de comprovar que quasi totes les assistents sabien llegir i escriure, ens vam adonar de que el principal problema que reflectien era la comprensió lectora.

Davant d'aquesta situació, vam haver de modificar i repensar la nostra planificació i adequar-lo a la nova situació. Per tant, vam decidir que abans de començar amb l'escriptura, en primer lloc havíem de centrarnos en la llengua oral, però sense deixar de costat l'altra tasca.

Amb motiu d'estar celebrant el Ramadà, els vam sol-licitar que ens contaren el motiu de la seua celebració, al mateix temps que també els vam demanar que ens contaren el seu lloc de procedència, per què havien decidit vindre a Espanya a viure i que ens detallaren les principals tradicions de la seua cultura. Així, vam aconseguir crear un clima acollidor, de confiança, respectuós, càlid i familiar.

La següent tasca, per a mantenir un clima dinàmic, va consistir en mostrar a les dones unes fitxes amb imatges d'objectes quotidians. Les mostràvem i demanàvem que les nomenaren en castellà $i$, després, que sortissin a la pissarra a escriure-la. Durant aquesta activitat, no interveníem, deixàvem que foren elles les que, ajudant-se mútuament, descobriren la paraula i la escrigueren correctament a la pissarra.

Després d'haver fet participar a totes les dones en aquesta tasca, vam decidir donar-les un fragment d'un llibre que contava la història i l'origen de les piràmides d'Egipte. Cada dona llegia un fragment per, després entre totes, esbrinar les paraules que no coneixien, sempre deixant que 
foren elles les que intervingueren, fent únicament de mers guies. En aquesta tasca ens vam assabentar del problema de comprensió lectora que tenien.

Abans d'acomiadar la primera sessió, els vam plantejar la possibilitat de centrar les següents classes a conèixer paraules de situacions quotidianes que es poden trobar dia a dia. En adonar-nos la seua confirmació, vam decidir que les properes sessions foren dedicades al coneixement de paraules mèdiques, administratives, $d$ 'aliments $i$ els diferents tipus de mesures.

La segona sessió, i a conseqüència de la gran dificultat que ens suposava reconèixer els noms de les nostres alumnes, vam decidir que per a practicar també l'escriptura, escriuríem en un paper el nostre nom i ens el penjaríem. Per a seguir amb l'ambient de respecte que volíem aconseguir, vam optar per escriure també el nostre nom al costat en àrab. Així, que s'adonessin que ens interessa igualment, i molt, la seua cultura i escriptura. Ràpidament, passarem al vocabulari que és la qüestió que més les preocupa.

Amb l'ajuda del centre, que ens va facilitar un esquelet i uns pòsters amb totes les parts del cos, vam començar nomenant les diferents parts d'aquest, preguntant primer si sabien el nom i, després, fent-les escriure'l a la pissarra. En aquesta part ens vam adonar que tenien dificultats en diferenciar els òrgans i amb el singular i el plural. Per tant, al mateix temps que els fèiem escriure el nom, practicàvem com seria l'article de la paraula i, el singular i el plural.

Una vegada comprovat el domini d'aquest material, vam optar per fer un joc simbòlic. Un de nosaltres va assumir el rol de metge i elles el de pacients. Després, i per a que practicaren més, van ser elles les que van assumir el rol de metge i pacients alhora, sols actuant nosaltres quan observàvem algun error que calia corregir.

Després d'aquesta tasca, que gràcies a la participació va ser molt profitosa i motivadora vam continuar treballant els noms de fruites, verdures, llegums.

En aquest cas, vam procedir com en l'activitat anterior, utilitzant el material que ens va facilitar el centre. Primer vam mostrar targetes amb fotos de diversos aliments, deixant que elles endevinaren el nom per després escriure'l a la pissarra. Deixarem que foren elles les que es corregiren unes a les altres. Vam aprofitar el joc amb els aliments per introduir les unitats de mesura.

Vam practicar de nou el joc simbòlic, assumint un altra vegada un component del nostre grup el rol de venedor, i les dónes de compradores. 
Després, com en la tasca anterior, vam canviar els rols deixant que les dónes foren les protagonistes, tant de venedores com fent de clientes.

Durant tot el matí ens vam adonar de la dificultat que tenen a l'hora de reconèixer i diferenciar grafies i fonemes d'alguns sons, quan i on s'han de ficar accents, quan ficar C, K, Z, G, J, B o V, per tant, els férem una mica d'introducció a les regles gramaticals.

Al finalitzar la sessió, les dones, per a mostrar-nos una part de la seua cultura, degut a la nostra curiositat del primer dia, ens van convidar a tastar les pastes, corder, pa i té típics de la seua terra que havien dut a classe.

La tercera i última sessió va ser molt dinàmica i es notava, encara més, les ganes d'aprendre i interès de les alumnes, ja que van acudir a la sessió amb llibreta per anar apuntant tot el que aprenien. També ens tenien més confiança i això es notava en el transcurs de la classe.

Per començar, vam fer un repàs de les lletres que presenten major grau de dificultat per a elles, grafies i els fonemes, accents, puntuació,..., en definitiva, un breu recorregut del que havíem vist el dia anterior. També vam repassar les parts del cos, les fruites i verdures per assolir coneixements.

Per primera vegada parlem dels accents, practiquem l'accentuació, i expliquem unes nocions bàsiques per a anar practicant a classe. Totes ixen a la pissarra per accentuar paraules.

Mitjançant un text adequat al seu nivell practicàrem la lectura i la comprensió lectora. Cada alumna llegeix unes línies en veu alta. Després, entre totes, intenten esbrinar el significat d'aquelles paraules que no comprenen i la seua pronunciació. Les paraules que no entenen, li les expliquem i elles les tornen a escriure a la pissarra.

També sorgeix el concepte de les paraules sinònimes i antònimes, i ho practiquem amb objectes quotidians que elles coneixen.

Una volta acabat de llegir el text, se'ls fa un dictat per a que practiquen l'escriptura. Tot seguit, cada alumna escriu a la pissarra una frase i, com sempre, entre elles fan la correcció si hi ha cap error.

Al ser l'última sessió, els vam demanar que ens feren una xicoteta avaluació sobre el taller que els havíem realitzat. D'aquesta forma van practicar l'escriptura lliure i van poder reflectir cóm s'havien sentit i si els havien agradat les classes i els nostres procediments.

També els vam dir que, encara que la nostra tasca finalitzava ací, podien contar en la nostra ajuda, ja que continuaríem visitant l'escola 
periòdicament per fer un seguiment del taller. A partir d'ara, serà una mare la que continuarà el taller amb dues classes setmanals.

Com a agraïment per la nostra desinteressada col·laboració, totes les mares ens van convidar a participar en un taller de cuina a l'escola la setmana següent. Un taller on cuinaríem el pa típic del Marroc, cous-cous amb pollastre i verdures i, dolços.

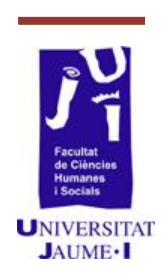

IV. Resultats

Tot i que aquesta experiència va ser curta en el temps, podem fer una aproximació als resultats que van emergir de l'experiència. En primer lloc, destaquem l'assistència de les mares al taller com un indicador que denota les ganes de participar d'algunes famílies del barri en el centre. Moltes mares van respondre positivament a la crida de l'escola i les classes que vam impartir van ser molt dinàmiques, participatives $i$ profitoses per part de les alumnes, que van mostrar gran interès i moltes ganes d'aprendre en totes les activitats que preparàrem. Això va desembocar en que volguessin venir a la segona sessió .

Tots hem aprés moltíssim: alumnes, mares, personal del centre... Aquesta experiència ha estat molt satisfactòria pel fet de permetre'ns poder conèixer de primera mà una cultura tan desconeguda per a nosaltres, però amb la que al mateix temps, convivim diàriament. Per altra banda, hem tingut l'ocasió de poder identificar paraules i costums inserides pels musulmans com a herència dels segles de convivència que hem compartit en l'Edat Mitjana, ja que també va ser un tema tractat en un dels nostres encontres.

Però una de les qüestions més important per a tots els membres del grup, sens dubte, ha estat el canvi de mentalitat i la desaparició de prejudicis que teníem i que bé des de casa, l'escola, la religió..., ens havien inculcat. Conviure en altres cultures, com la musulmana, xinesa, gitana, romanesa,..., és ampliar els nostres coneixements, obrir la ment, acceptar uns altres estils de vida, el que suposa créixer com a persona individual $i$ créixer com a part d'un col-lectiu. Açò inclou tindre moltes més perspectives a l'hora de saber enfrontar-nos a qualsevol situació que la vida, i sobre tot, a creure en valors tan fonamentals com són la inclusió, la diversitat, el respecte, la amistat...

En el marc actual, hi ha individus que tenen la sensació de que acceptar altres estils de vida es posar en perill la seua pròpia identitat com a poble, i sobre tot, algunes persones tenen la sensació de que si deixem integrar a gent d'una altra cultura a la nostra vida o societat, va a ser perjudicial per a nosaltres. Aquesta experiència ens ha demostrat que tals creences només són una fal-làcia. Compartir i mesclar quelcom tan important com és la llengua només reporta beneficis, ja que com bé diu Tusón en el seu 
llibre "Patrimoni Natural, Elogi i defensa de la diversitat lingüística» (2004), "el coneixement de més d'una llengua sempre suma, mai no resta». És una màxima que no hem d'oblidar. I menys en el context en que ens trobem actualment.

Amb tot açò, no sols hem gaudit d'aquesta experiència nosaltres, també les dones que van acudir al nostre taller, i que no hi ha que oblidar que han sigut les principals protagonistes d'aquest treball. Elles, no sols han aprés i ampliat els seus coneixements de la nostra llengua, punt principal per el qual van venir a les nostre classes, sinó també han trencat la barrera de sentir-se inferiors a la resta de la comunitat, tant en el seu entorn de barri, com en l'entorn escolar dels seus fills.

Tots hem estat molt implicats des del començament $\mathrm{i}$ hem tingut una evolució i progressió constant.

L'impacte a l'escola també ha estat gran, immediat i directe. Les mares han passat de ser personatges passius i secundaris, a formar part de l'entramat del sistema educatiu dels seus fills i, sobre tot, a participar i integrar-se en el centre, ja que han tingut la possibilitat de mantenir contacte directe amb direcció, mestres, cuinera, voluntaris...

Amb el taller de cuina, també han tingut l'oportunitat de conèixer i utilitzar les instal-lacions del centre per primera vegada: classes, cuina, menjador... Implicant-se d'una forma activa i directa, mostrant interès real. Hi ha que dir que aquest taller ha sigut fonamental per a elles. Ha estat la eina que els feia falta per a sentir-se realitzades i incloses, fer-les sentir que també poden ensenyar i ajudar als mestres en les tasques que els plantegen. En definitiva, han perdut la por a sentir-se infravalorades. Han aprés que amb tasques tan senzilles com aquestes, poden formar part de la comunitat educativa, tal i com els demanaven els responsables del centre des de feia temps.

Així ha quedat patent quan han comunicat al centre les seues ganes de continuar formant-se i demanant-los consell sobre en què poden ajudar al centre per a què els seus fills el dia de demà puguen tenir més oportunitats de futur de les que elles han tingut.

La nostra satisfacció més gran és que, no sols hem prestat un servei que el centre necessitava, sinó que gràcies a aquest taller d'introducció a la llengua espanyola, s'han establert nous llaços, estretit relacions, creat pons per a futures propostes entre els pares i els docents. Al mateix temps que hem aprés, per part de tots, tolerància i respecte cap a altres cultures. Sempre, sense perdre de vista que, tota aquesta tasca es fa pels xiquets.

Per part del centre, tant el director com la cap d'estudis, ens han mostrat sempre el seu suport, satisfacció i gratitud pel desenvolupament del 
nostre servei des de l'inici de la nostra intervenció. Han quedat molt gratulats pel bon resultat obtingut, malgrat ser aquesta la primera intervenció de l'escola amb pares en la nova etapa com a comunitat d'aprenentatge.

\section{Discussió i conclusions}

L'experiència ha estat molt positiva tot i que abans de la primera sessió, estàvem intranquils i nerviosos, ja que no sabíem amb quina quantitat d'alumnes ens trobaríem, ni el nivell, ni la predisposició que tindrien. Era una aposta arriscada, però per les necessitats del centre necessària. Finalment, acudiren 19 dones d'origen mussulmà i 1 espanyola.

Un altre punt que ens preocupava era si seríem capaços de transmetre tot el que volíem, i més si podríem aconseguir-ho amb adults d'una cultura diferent a la nostra. Però tot barrejant les ganes de fer-ho bé, la constant preparació de les classes i les ganes d'aprendre de les alumnes, tot ha anat rodat, donant-nos i enduent-nos la impressió de què ha estat una experiència molt enriquidora per tothom.

D'una altra banda, des del primer moment vam descobrir que tot el personal del centre forma un equip molt càlid i familiar. Tant es així que, gracies a les atencions que vam rebre, la total llibertat per fer servir materials i l'ajuda que ens van oferir, ens vam sentir a l'escola com uns docents més. Aquest marc tan adient ens va permetre guanyar confiança en nosaltres mateixos malgrat la dificultat a l'hora d'abordar el taller.

Als tres membres del grup ens ha estat molt gratificant l'experiència, ja que hem tingut l'oportunitat d'entrar a un centre escolar, veure cóm funciona $i$, tot i que no vam treballar amb xiquets que era el nostre desig, sí que vam tindre l'oportunitat d'entrar a les aules d'infantil per observar com es treballa amb els més menuts.

La nostra intenció es la de seguir els passos del taller introducció a la llengua espanyola que vam començar, ja que la persona que es queda al càrrec així ens ho ha transmès. De fet, alguns membres del grup ja tenen clar que les seues pràctiques les volen desenvolupar en aquest centre.

Aquest servei no sols ha estat important per la feina que hem desenvolupat, sinó que també ens ha donat la oportunitat de conèixer de primera mà què és i com funciona una Comunitat d'Aprenentatge, ja que des dels nostres inicis en la carrera sempre se'ns havia parlat d'aquest tipus de centres però mai havíem tingut l'oportunitat de comprovar-ho «in situ». N'hi ha molt pocs centres amb aquesta metodologia, i menys a la província de Castelló. Per tant, el benefici nostre ha estat una doble, al participar i conèixer cóm funcionen aquest tipus d'escoles amb una 
metodologia tan avantguardista i de la que tan hem sentit parlar, perquè tots sabem que no és el mateix conèixer-les teòricament que gaudir de l'oportunitat de participar directament en una d'elles. Finalment, ens agradaria donar les gràcies a tots el membres d'aquest centre per havernos donat suport, recolzament i aquesta oportunitat

\section{Bibliografia}

APARICI, R. (2003): Comunicación educativa en la sociedad de la información, Madrid, UNED.

CAstells, M. (2001): La era de la información. Vol. 1. La sociedad red, Madrid, Alianza ed.

De la Cerda, M., i altres (eds) (2008): Amics i amigues de la lectura en Aprenentatge servei i responsabilitat social de les universitats, Barcelona, Octaedro.

DeloRS, J. (1996): La educación encierra un tesoro, Madrid, UnescoSantillana.

FLeChA, R. i L. PUIGVERT (2008). Universitat de Barcelona. España.

FREIRE, P. (1997): La educación como práctica de la libertad, Xile, Siglo XXI editores, s.a. de c.v.

Martín, X. i altres (eds.) (2006): Carmelles en l'Escola Santa Anna, Quaderns de Pedagogia, 357, 71-72.

Publicacions de la Universitat Jaume I de Castelló (2011). Servei de Comunicació i Publicacions Campus del Riu Sec. Col-lecció Sapientia, 56.

PUIG RoviRA, J. M. i altres (eds.) (2010): Servei d'Escola i Entorn i el Servei d'Ordenació Curricular del Departament d'Educació. Xarxa telemàtica educativa de Catalunya. Departament d'ensenyament de la Generalitat Catalana.

Tuson, J. (2004): Patrimoni natural, Elogi i defensa de la diversitat lingüística. Barcelona, Empúries, Biblioteca Universal. 